\title{
DIRECT TENSION RECORDING FROM SMOOTH MUSCLE OF RESISTANCE VESSELS FROM VARIOUS ORGANS*
}

\author{
DAVID F. BOHR, M.D., PATRICIA L. GOULET, and AlbBRTO C. TAQUini, Jr.† M.D.
}

Extensive evidence demonstrating the functional individuality of different vascular beds has been mustered by Green and Kepchar. ${ }^{1}$ Teleologically, this individuality is appropriate to meet the specialized demands placed on the circulation in different tissues under various physiologic conditions. Mechanistically, the individuality may reflect differences in one or more of the following parameters: (1) vascular structure, (2) neurogenic control, and (3) smooth muscle responsiveness.

The current study was undertaken to evaluate and characterize possible differences among smooth muscle preparations obtained from resistance vessels of various tissues. Small resistance vessels were used instead of large conduit arteries because the pattern of flow distribution through various organs and tissues is determined primarily by the degree of contraction of the smooth muscle in the small vessels. The vessels used were 200 to $300 \mu$ in diameter. Studies, such as those of Haddy, ${ }^{2}$ in which pressures are recorded at several sites along the axis of flow in the vascular tree, have demonstrated that vessels of this size afford significant resistance to flow. Whether or not they are called arterioles is then a matter of semantics not related to this functional property.

Since isolated muscle preparations were used, observed differences would reflect intrinsic characteristics of the several types of smooth muscle; characteristics which persisted even after the muscles were placed in a common environment of Krebs solution. Smooth muscle from resistance vessels obtained from mesentery, kidney, lung and brain each evidenced consistent individualities in this environment.

\section{METHODS}

The resistance vessel is dissected from its parent tissue within $24 \mathrm{hr}$. after removal from dog

* Supported by grant H-3756 C2 from the National Heart Institute, P.H.S.

$\dagger$ Current address: Dr. Alberto C. Taquini, Jr., Centro de Investigaciones Cardiologicas, Azcuenaga 985, Buenos Aires, Argentina. or rabbit. This period of storage at $4^{\circ} \mathrm{C}$ does not alter smooth muscle performance. With the aid of a dissecting microscope, a vessel, 200 to $300 \mu$ in diameter, is teased free from its surrounding parenchyma, fat and connective tissue for a length of 3 to $5 \mathrm{~mm}$. Fine surgical silk thread is then tied firmly around one end of the resistance vessel which is still attached to the tissue from which it has been isolated. The following technique is then used to cut a helical strip from the vessel wall so that the long axis of the strip is virtually parallel to the long axis of the muscle fibers. The vessel is first mounted on a stainless steel wire. These wires, obtained from Becton, Dickinson and Co., are standard needle stilets sharpened at one end. The sharp end of the wire is threaded into the lumen of the vessel at its free end until it reaches a point about $100 \mu$ from the knot. At this point it is jabbed through the vessel wall (fig. 1). The rod is then pulled on through until the vessel section is midway along the rod. The vessel is freed from the rest of the tissue by cutting just proximal to the knot. The entire dissection up to this point is carried out in a petri dish under Krebs solution. The resistance vessel is now draped with moist gauze and the two ends of the wire are mounted in collets of appropriate size which are secured in the chucks of a jeweler's lathe. Once in position on the lathe the gauze is removed and Krebs solution is dripped continuously on the vessel.

The modified jeweler's lathe has the following special features designed to facilitate sectioning of the small vessels: (1) two synchronously gear-driven chucks; (2) a moving slide rest which allows cutting of a strip as small as $50 \mu$ wide (this is equivalent to cutting 500 threads to the inch); (3) a reversible variable speed motor which rotates the lathe as slowly as one turn per minute; (4) a vibrating motor, attached to a blade holder on the slide rest, which gives the blade a sawing motion with a stroke of about $5 \mu$; and, (5) a small chip of the cutting edge of a razor blade for slicing the vessel.

The procedure for the actual slicing is as 

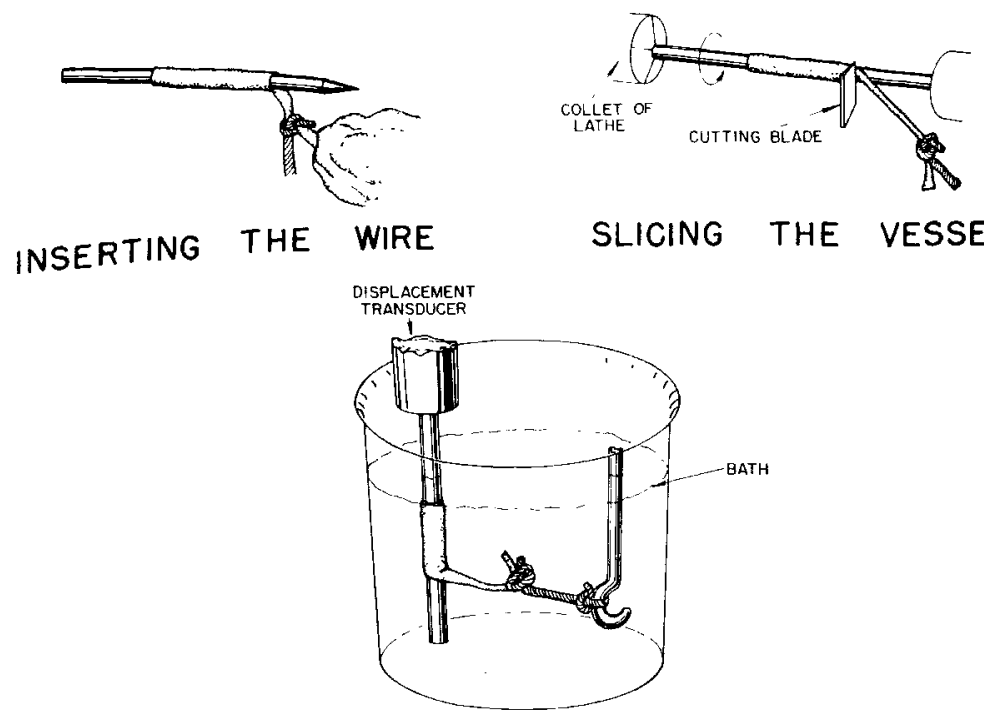

\section{RECORDING TENSION}

Ftci. 1. Preparation of strip from resistance vessel. A section of a vessel freed from surrounding tissue is threaded on a steel wire. Wire and vessel are mounted in a jeweler's lathe and a helical strip is cut trom the vessel as it rotates. The strip is mounted by means of the wire which remains in the vessel in a displacement transducer from which phasic changes in tension are recorded.

follows: (1) the wire is stretched tightly between the tro chucks by pulling on the right hand, morable chuck before it is sccured into position; (2) the slicing blade is advanced until it presses firmly against the steel wire just distal to the puncture hole that the wire has made in the ressel wall; (3) the thread on the free end of the ressel is then held in such a position that the rotation of the wire turns the vessel wall into the slicing blade. In this fashion a helical strip, 1 to $2 \mathrm{~mm}$ in length, is sliced from the "thread end" of the vessel (fig. 1).

In order to record tension developed by the lulical strip, the wire is then removed from the whllet and one end is mounted in a Grass disllarement transducer. The thread attached to the free end of the strip is tied to a fixed glass rool in a bath of Krebs solution maintained at $x^{3} \mathrm{C}$.

In order to obtain comparable strips from large conduit vessels the gross slicing technique if Furchgott and Bhadrakom ${ }^{3}$ is employed. Tensions monitored by the strain gauge translucer are recorded on a Grass direct-writing migraph.

The Krebs solution bathing the muscle preparations is aerated with 95 per cent $\mathrm{O}_{2}$ and
5 per cent $\mathrm{CO}_{2}$ giving a $\mathrm{pH}$ of 7.35 at the following millimolar composition: $\mathrm{NaCl}, 118.9 ; \mathrm{KCl}, 4.7$; $\mathrm{KH}_{2} \mathrm{PO}_{4}, 1.2 ; \quad \mathrm{MgSO}_{4}, 1.2 ; \mathrm{NaHCO}_{3}, 14.9$; dextrose, 5.6; $\mathrm{CaCl}_{2}, 2.5$; sucrose, 49.9 ; and calcium disodium versenate, .026 . The last is included to chelate trace amounts of heavy metal which would otherwise catalyze the auto-oxidation of catecholamines.

When the vascular smooth muscle is mounted in the bath, a tension of between 100 and 200 $\mathrm{mg}$ is applied to a resistance vessel strip, and a tension of approximately $500 \mathrm{mg}$ is applied to a preparation from a large conduit tube. At this tension these vessels have been found to develop optimal phasic tension in response to specific stimuli. The strips are left in the Krebs bath at $38^{\circ} \mathrm{C}$ for at least 2 hours to allow their responses to become stabilized. This stabilization period is required presumably for the smooth muscle cells to develop stable transmembrane electrolyte gradient conditions. ${ }^{4,5}$

\section{RESULTS}

Comparison of smooth muscle from conduit and resistance vessels. In the comparison of smooth muscle from large and small vessels the responses of aorta were recorded simultaneously with those 


\section{EPINEPHRINE DOSE-RESPONSE (MIGROGRAMS PER LITER)}
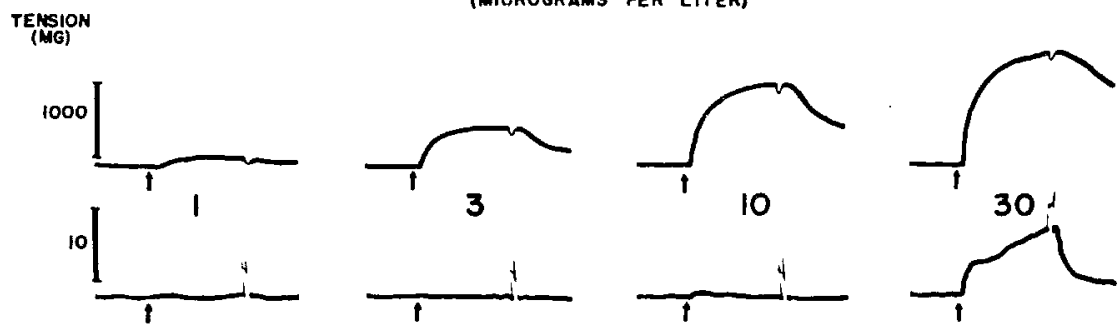

AORTA

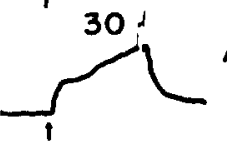

ARTERIOLE
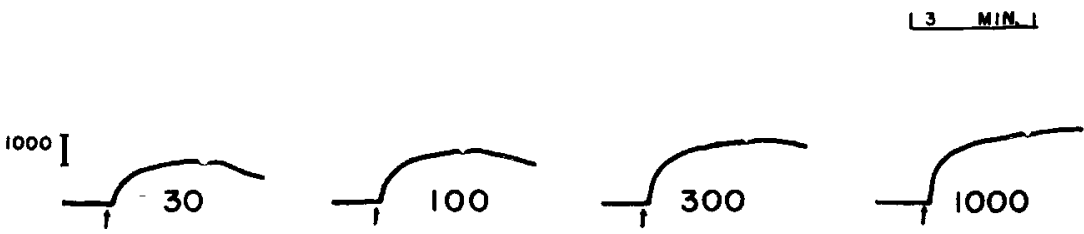

AORTA
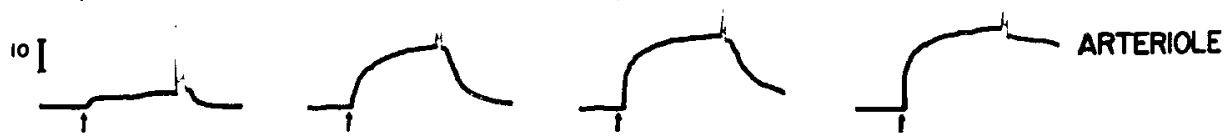

Fig. 2. Comparison of responses of smooth muscle from resistance and conduit vessels. Rabbit smooth muscle preparations obtained from mesenteric resistance vessel and from the aorta, mounted in a common bath of Krebs, were stimulated with increasing concentrations of epinephrine. Arrows indicate time of injection and mixing of epinephrine in bath of Krebs solution. Numbers represent epinephrine concentration in $\mu \mathrm{g} / \mathrm{l}$. Removal of the epinephrine after $2 \frac{1}{2}$ minutes is indicated by the spiking rinse artifacts in the tracings. Note that the sensitivity of the recording system was reduced to obtain the responses at the higher concentrations.

of a resistance vessel of the mesentery. Comparative studies were made on these two preparations from 12 rabbits. In all such studies the two preparations shared a common bath so that they were exposed to the same environment and subjected to identical humoral stimuli. Figure 2 depicts the record of a dose-response study using epinephrine. It is evident that the threshold for epinephrine response in the aorta is approximately $1 \mu \mathrm{g} / 1$ (final bath concentration), while that for the mesenteric resistance vessel is at least 10 times this concentration. This difference was observed consistently (fig. 8). Qualitative differences between the effects of altered potassium concentration on smooth muscle from these two vessels have already been described. ${ }^{6}$ Although it is not the object of the current study to compare responses of smooth muscle from conduit and resistance vessels, these observed differences demonstrate that results on large vessels cannot be interpreted as being representative of the characteristics of the smooth muscle concerned with the control of vascular resistance.

Mesenteric resistance vessels. The mesenteric resistance vessel is the one most easily dissected from its surrounding tissue, and the one that we have studied most extensively. Observations have been made on strips of these vessels from 24 rabbits and 15 dogs. These observations have failed to demonstrate any species difference which was greater than the degree of variability in the responses within one species.

Responses of the mesenteric resistance ressels to the following agents were evaluated: potassium chloride, epinephrine, norepinephrine, 5-hydroxytryptamine, angiotensin II amide, vasopressin and acetylcholine. In most studies simultaneous observations were made of the responses of a resistance vessel from another tissue. In general smooth muscle from the mesenteric resistance vessel was the most responsive. Repeated stimulation of the mesenteric vessel with potassium chloride, epinephrine or norepinephrine produced quantitatively reproducible responses in a given preparation, and the threshold for responsireness to these constrictor agents was relatively c(t)1sistent among mesenteric vessels obtained from different animals.

Although the mesenteric resistance ressels con- 


\section{COMPARISON OF MESENTERIO AND RENAL VASCULAR RESPONSES}
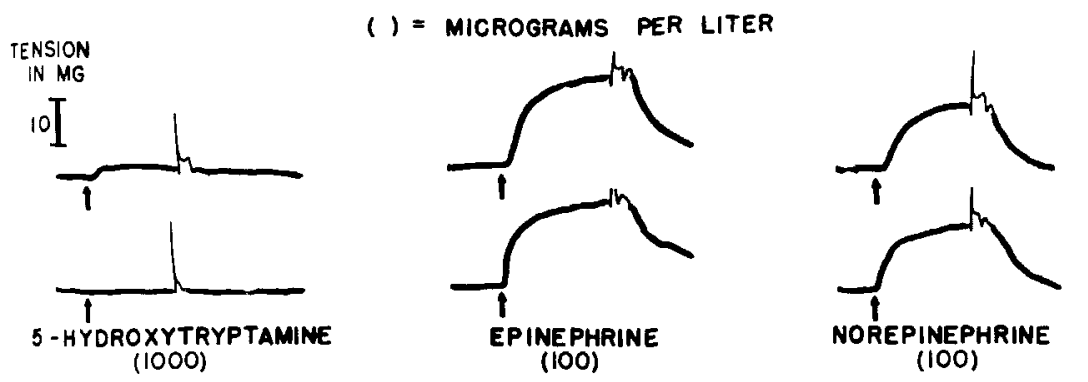

MESENTERIC

2 MIN

\section{RENAL}

\section{MESENTERIC}

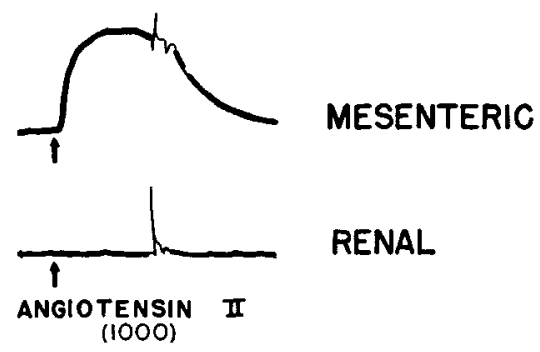

\section{RENAL}

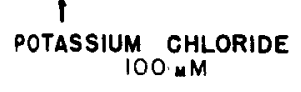

Fig. 3. Comparison of responses of smooth muscle from dog mesenteric and renal resistance vessels. Ilthough somewhat equal responses were obtained when epinephrine, norepinephrine or potassium thloride was administered, the renal vessel failed to respond to 5 -hydroxytryptamine or to angiotensin II amide.

sistently responded to stimulation by adequate whentrations of 5-hydroxytryptamine, angiotensin and vasopressin, each of these agents produced a rapid tachyphylaxis in a given preparation and the threshold concentration for response varied widely from one preparation to another. The muscle recovered from its tachyphylaxis to these agents within several hours so it was possible to obtain at least fragmentary dose-response curves. Smooth muscle from the mesenteric resistance vessel did not contract in response to acetylcholine at any concentration tested.

Renal resistance vessels. Six strips of dog renal resistance vessels have been studied. There was a greater similarity between the responses of renal and mesenteric resistance vessels than between those of any other pair of vessels studied. Nevertheless, consistent differences were noted; the most striking was that the renal vessel either failed to respond to angiotensin (fig. 3) or the reyonse was small. This vessel also responded less well to 5 -hydroxytryptamine or to vasopressin than did the mesenteric resistance vessel (fig. 3 and 4). On the other hand smooth muscle from renal resistance vessels appeared to be slightly more sensitive to epinephrine than that from the mesenteric resistance vessels (fig. 8).

Pulmonary resistance vessels. Smooth muscle preparations of these vessels from 8 rabbits and 2 dogs were studied. No species difference was evident. Consistent and striking differences exist between the responses of pulmonary resistance vessels and those already described. No response to epinephrine or norepinephrine was seen unless very high concentrations of these catecholamines were administered (figs. 4 and 5). When responses to epinephrine did occur they were not immediate, as they were in the other resistance vessels, but the onset was delayed for 30 seconds or more, suggesting that the mechanism for this response is similar to that of the "slow component" of an epinephrine response observed in aortic smooth muscle. ${ }^{7}$ In contrast to this refractoriness to catecholamines, the isolated pulmonary resistance vessel did contract in 


\section{COMPARISON OF PULMONARY AND RENAL VASCULAR RESPONSES}

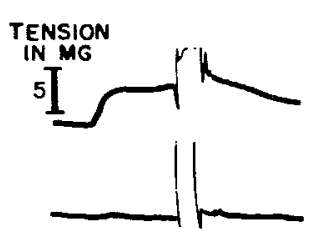

5 - HYDROXYTRYPTAMINE (100)

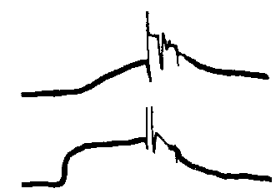

POTASSIUM CHLORIDE $50 \mathrm{mM}$
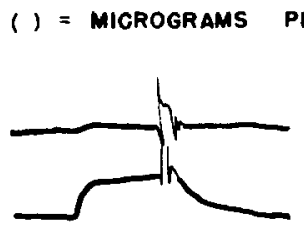

EPINEPHRINE (30)

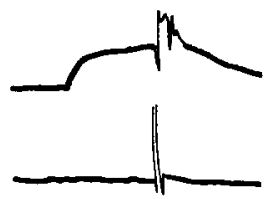

ACE TYLCHOLINE (1000)
PER LITER

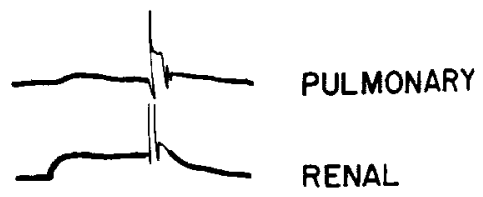

NORE PINEPHRINE

(3O)

2 MIN.

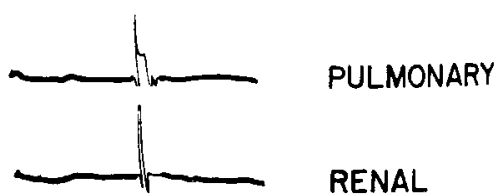

VASOPRESSIN $400 \mathrm{mU} / \mathrm{ML}$

Fig. 4. Comparison of responses of smooth muscle from dog pulmonary and renal resistance vessels. Striking differences are seen in that the renal vessel failed to respond to 5-hydroxytryptamine or to acetylcholine while the pulmonary vessel failed to respond to epinephrine or to norepinephrine.

\section{PULMONARY RESPONSES}

\section{( ) = MICROCRAMS/LITER}
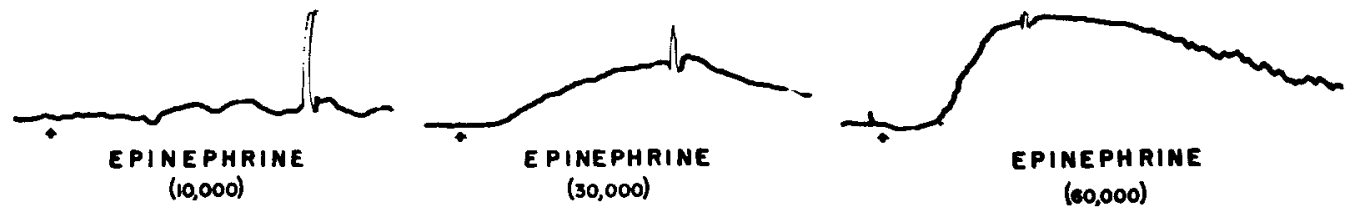

FIG. 5. Responses of rabbit pulmonary resistance vessel to high concentrations of epinephrine. In contrast to the usual characteristic of an epinephrine response the onset of these contractions is delayed 30 seconds after the administration of epinephrine.

response to acetylcholine. In both the dog and rabbit this agent caused contraction at threshold concentrations between 30 and $100 \mu \mathrm{g} / \mathrm{l}$. Smooth muscle from the pulmonary resistance vessel was more responsive than that from the mesentery to 5-hydroxytryptamine. It was equally responsive to potassium chloride and angiotensin but only poorly responsive to vasopressin.

Cerebral resistance vessels. The individuality of smooth muscle of cerebral resistance vessels is most striking. In none of 12 such preparations from dog brain did this smooth muscle show more than a minimal response to even the highest con- centrations of catecholamines (figs. 6 and 7). On the other hand, smooth muscle from cerebral vessels was consistently more responsive to 5 hydroxytryptamine than was that from the mesenteric vessels. The threshold concentration for response of the cerebral resistance vessels to 5-hydroxytryptamine was less than the threshold concentration of epinephrine required to produce a contraction of the mesenteric resistance ressel. The cerebral vessel failed to respond to angiotensin or to acetylcholine but did respond to vasopressin and consistently responded to potassium chloride. 


\section{COMPARISON OF MESENTERIC AND CEREBRAL VASCULAR RESPONSES}

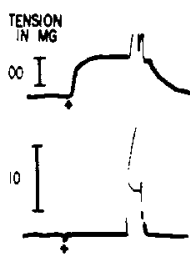

EPINEPHRINE

(100)

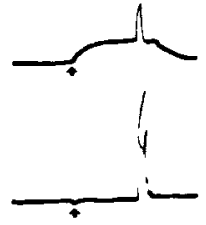

NOREPINEPHAINE

(100)

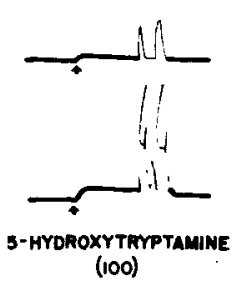

\section{Min.}

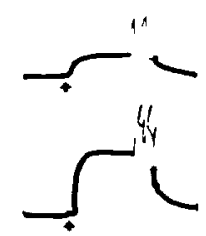

POTASSIUM CHLORIDE $50 \mathrm{mH}$

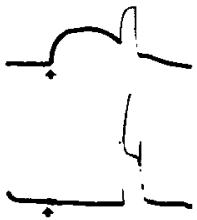

ANGIOTENBNII

$(500)$

MESENTERIC

CEREBRAL
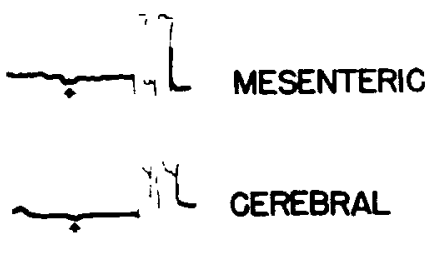

SODIUM GHLONIDE

so ind

FIG. 6. Comparison of responses of smooth muscle from mesenteric and cerebral resistance vessels. lote that the smooth muscle from cerebral vessels failed to respond to epinephrine or norepinephrine while it was more responsive than that of the mesenteric vessels to 5 -hydroxytryptamine.

\section{DIFFERENCES IN VASCULAR RESPONSE}

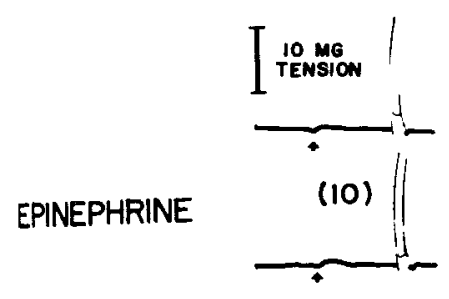

3 MIN.J

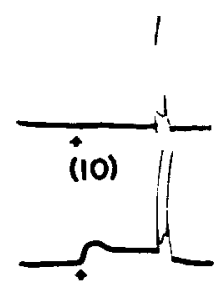

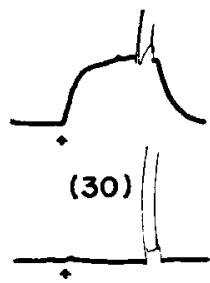

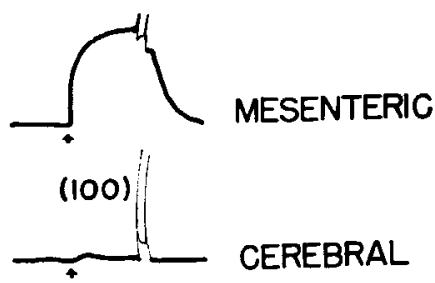

( )=MICROGRAMS PER LITER

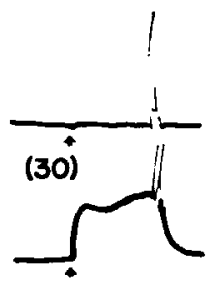

MESENTERIC

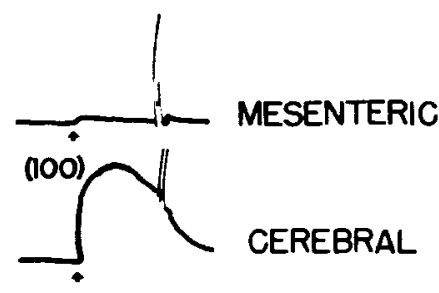

Fig. 7. Dose-response studies of cerebral and mesenteric resistance vessels to epinephrine and to indroxytryptamine. Note that the response of the smooth muscle of the cerebral vessel to 5-hydroxyjutamine is roughly equivalent to the response of the smooth muscle of the mesenteric vessel to :inephrine. 


\section{DISCUSSION}

Individuality of the responsiveness of smooth muscle from resistance vessels in the various vascular beds was evident with each of the vasoactive agents studied, except potassium chloride. This individuality in response to epinephrine is demonstrated in the threshold data summarized in figure 8; all experiments are included in which satisfactory dose-response curves were obtained. Smooth muscle from renal resistance vessels may be slightly more sensitive to epinephrine than is that from mesenteric vessels. Smooth muscle from resistance vessels from the lung and brain is extremely refractory to this agent. This pattern of responsiveness is duplicated for norepinephrine except that the concentration required is 2 or 3 times that for epinephrine (fig. 9).

EPINEPHRINE

Threshold concentrations for

response of vorious vessels

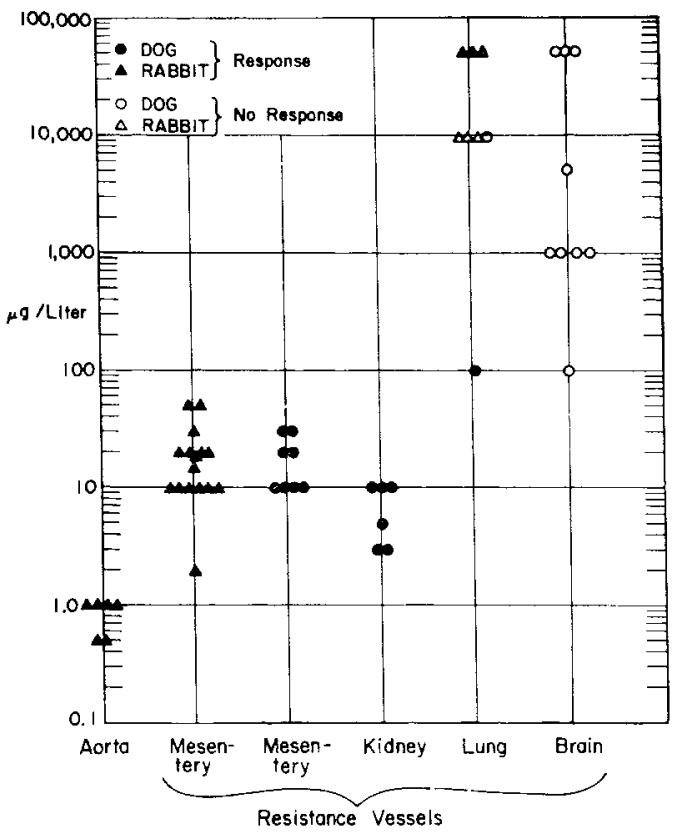

Frg. 8. Comparison of threshold concentrations for response of smooth muscle from various vessels to epinephrine. Each point represents an individual animal. Smooth muscle from the rabbit aorta is more sensitive to epinephrine than is that from the mesenteric resistance vessel. Sensitivity of the smooth muscle from the renal resistance vessel appears to be intermediate between that from the mesentery and from the aorta. Smooth muscle from the lung and brain are relatively refractory to stimulation by epinephrine.
EPINEPHRINE and NOREPINEPHRINE

Comparison of threshold concentrations for response of various vessels

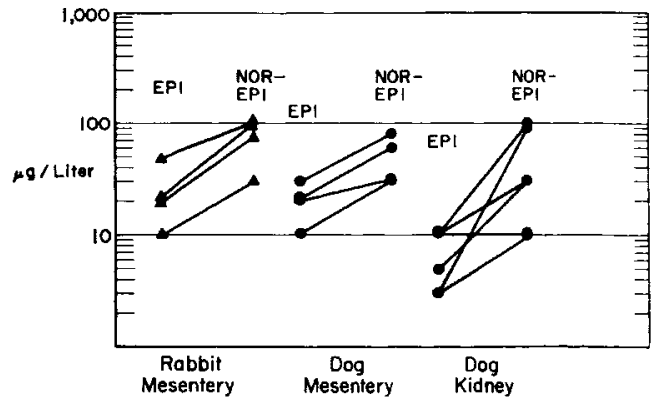

Fig. 9. Relative sensitivity of various vascular beds to epinephrine and to norepinephrine. Threshold concentrations determined from doseresponse curves of 8 mesenteric and 6 renal resistance vessels were measured. The threshold concentration required for a norepinephrine response is consistently 2 to 3 times as great as that required for the response to epinephrine.

The order of responsiveness of the various vascular beds to 5-hydroxytryptamine is: cerebral $>$ pulmonary $>$ mesenteric $>$ renal. Angiotensin was equally effective in producing a response of mesenteric and pulmonary resistance vessels while renal and cerebral resistance vessels were refractory to this agent. Vasopressin on the other hand was more effective in producing responses in the mesenteric and cerebral ressels than in the renal and pulmonary vessels.

Differences in responsiveness of isolated smooth muscle preparations from various larger vessels have been described by Dodd and Daniel ${ }^{8}$ and by Rondell and Gross. ${ }^{9}$ These studies, together with the current observations, must be interpreted as indicating that the differences are myogenic. In the current state of our ignorance about the mechanism by which the vasoactive agents produce contraction, it is convenient to attribute these results to differences in receptor substances on vascular smooth muscle cells from various sources. These differences persist when the smooth muscle preparations are placed in a common environment of Krebs solution.

In contrast to this individuality in responsireness to physiologic humoral agents, is the consistent response of all vascular smooth muscles to potassium chloride. In all cases this muscle contracted when exposed to a threshold concentration of 20 to $30 \mathrm{~mm}$ of $\mathrm{KCl}$. This observation 
suggests that the potassium cation activates some mit of the contractile machine which is common in rascular smooth muscle from these various - ures. By analogy with other excitable tissue, it - reasonable to consider that potassium chloride may initiate the contractile response by causing ell membrane depolarization.

Advantages of studies conducted on isolated tisues rather than in vivo rest in the fact that the isolated preparation permits control of the enrironment of the vascular smooth muscle, and is direct recording of its mechanical response. It s reasonable to question whether the responses userved in the isolated system are similar to those that occur in vivo. Results obtained in the current study suggest that consistent differences do exist between the responses of vascular smooth muscle in vivo and those obtained in vitro; thus the preparation as it is studied in the isolated bath is completely relaxed, while vascular smooth muscle in vivo is known to be tonically contracted. Furthermore, acetylcholine which is known to rroduce only a relaxation of smooth muscle of resistance vessels in vivo, produces a contraction of the isolated smooth muscle from pulmonary resistance vessels. It is reasonable to postulate that many factors both intra- and extraluminal alter the responses of vascular smooth muscle in mo. Definition and analysis of differences between in vivo and in vitro responses should lead to knowledge of significant in vivo environmental influences such as may reside in the plasma or in parenchymal metabolites.

\section{SUMMARY}

A method is described for the preparation of mooth muscle strips from resistance vessels 200 to $300 \mu$ in diameter. Contractions were recorded when such preparations were stimulated by various physiologically vasoactive agents. Individuality of the responses of smooth muscle obtained from mesenteric, renal, pulmonary and cerebral resistance ressels was demonstrated when they were stimulated with epinephrine, norepinephrine, 5-hydroxytryptamine, angiotensin II amide or vasopressin. Smooth muscle from all resistance vessels responded similarly when stimulated with potassium chloride.

\section{Dr. David F. Bohr \\ Department of Physiology University of Michigan Ann Arbor, Michigan}

\section{REFERENCES}

1. Green, H. D., and Kepchar, J. H.: Control of peripheral resistance in major systemic vascular beds. Physiol. Rev., 39: 617, 1959.

2. Hador, F. J.: Local effects of sodium, calcium and magnesium upon small and large blood vessels of the dog forelimb. Circulation Res., 8: 57, 1960 .

3. Ftrchiot, R. F., and Bhadrakom, S.: Reactions of strips of rabbit aorta to epinephrine, isopropylarterenol, sodium nitrite and other drugs. J. Pharmacol. \& Exper. Therap., 108: 129, 1953.

4. Dawkins, O., And Bohr, D. F.: Sodium and potassium movement in the excised rat aorta. Am. J. Physiol., 199: 28, 1960.

5. Barr, L., Bohr, D. F., AND Headings, V.: Recovery of carotid artery strips from cold storage. Fed. Proc., 19: 258, 1960.

6. Bohr, D. F., And Goulet, P. L.: The role of electrolytes in the contractile machinery of vascular smooth muscle (In press).

7. Brodie, D. C., Bohr, D. F., ANd SMIT, J.: Dual contractile response of the arta strip. Am. J. Physiol., 197: 241, 1959.

8. Dodd, W. A., ANd Daniel, E. E.: Vascular muscle reactivity. Circulation Res., 8: 446, 1960.

9. Rondell, P., and Gross, F.: Method for isometric recording from isolated vessels under various conditions. Helvet. physiol. et pharmacol. acta, 18: 1,1960 . 